\title{
Near-Infrared Spectroscopy for Objectifying Cerebral Effects of Laser Acupuncture in Term and Preterm Neonates
}

\author{
Wolfgang Raith, ${ }^{1,2}$ Gerhard Pichler, ${ }^{1}$ Iris Sapetschnig, \\ Alexander Avian, ${ }^{3}$ Constanze Sommer, ${ }^{1}$ Nariae Baik, ${ }^{1}$ Martin Koestenberger, ${ }^{4}$ \\ Georg M. Schmölzer, ${ }^{1,5,6}$ and Berndt Urlesberger ${ }^{1,2}$ \\ ${ }^{1}$ Division of Neonatology, Department of Paediatrics, Medical University of Graz, Auenbruggerplatz 30, 8036 Graz, Austria \\ ${ }^{2}$ Research Group for Paediatric Traditional Chinese Medicine, TCM Research Centre Graz (Acupuncture Research), \\ Medical University of Graz, Auenbruggerplatz 30, 8036 Graz, Austria \\ ${ }^{3}$ Institute for Medical Informatics, Statistics and Documentation, Medical University of Graz, Auenbruggerplatz 2, 8036 Graz, Austria \\ ${ }^{4}$ Division of Pediatric Cardiology, Department of Pediatrics, Medical University of Graz, Auenbruggerplatz 34/2, 8036 Graz, Austria \\ ${ }^{5}$ Department of Pediatrics, University of Alberta, Edmonton, Alberta, Canada T5H3V9 \\ ${ }^{6}$ Neonatal Research Unit, Royal Alexandra Hospital, 10240 Kingsway Avenue NW, Edmonton, Alberta, Canada T5H3V9
}

Correspondence should be addressed to Wolfgang Raith; wolfgang.raith@klinikum-graz.at and

Berndt Urlesberger; berndt.urlesberger@medunigraz.at

Received 12 March 2013; Revised 22 April 2013; Accepted 26 April 2013

Academic Editor: Gerhard Litscher

Copyright (C) 2013 Wolfgang Raith et al. This is an open access article distributed under the Creative Commons Attribution License, which permits unrestricted use, distribution, and reproduction in any medium, provided the original work is properly cited.

\begin{abstract}
Laser acupuncture (LA) becomes more and more relevant in neonates and infants. With near-infrared spectroscopy (NIRS), a continuous and noninvasive measurement of tissue oxygenation is possible. Aim was to investigate, whether the application of LA was associated with any changes in regional cerebral oxygen saturation $\left(\mathrm{rcSO}_{2}\right)$ in term and preterm neonates. The study included 20 neonates (12 males, 8 females). The Large Intestine 4 acupuncture point (LI 4, Hegu) was stimulated by a microlaser needle (10 mW, $685 \mathrm{~nm}$ laser needle EG GmbH, Germany) for 5 minutes, bilaterally. All neonates underwent polygraphic recording during undisturbed daytime sleep, including heart rate (HR), peripheral oxygen saturation $\left(\mathrm{SpO}_{2}\right)$, and measurement of nasal flow. Using NIRS, $\mathrm{rcSO}_{2}$ was measured continuously. Cerebral fractional tissue oxygen extraction (cFTOE) was calculated. We did not observe any significant changes in $\mathrm{SpO}_{2}$ and $\mathrm{HR}$ values during the whole observation period. However, there was a significant decrease in $\mathrm{rcSO}_{2}(P=0.003)$ within postintervention period, accompanied by a significant increase in cFTOE $(P=0.010)$ in postintervention period.
\end{abstract}

\section{Introduction}

There is an increasing interest in complementary and alternative medicine (CAM) in particular in herbal medicine, homeopathy, and traditional Chinese medicine (TCM) to treat the pediatric population [1-3]. TCM has been practiced in China for over 2000 years as the main form of medical treatment before the introduction of western medicine approximately 100 years ago. TCM includes Tuina (i.e., Chinese massage at acupoints), moxibustion, and all types of acupuncture (acupressure, needle acupuncture, electric acupuncture, and laser acupuncture (LA)) [4]. Positive effects of acupuncture on reduction of pain and agitation in children have been reported [5]. However it is unknown whether repeated needle stimulation may alter sensory processing and responses to subsequent painful stimuli [6] or demonstrates an increased infection risk in premature babies [7]. LA application is painless and can avoid infections, which could be an important alternative to manual acupuncture in infants [8-14]. However, the applied doses, duration of stimulation, peripheral, and central effects of LA are an ongoing discussion $[15,16]$. Evidence derived from functional magnetic resonance imaging demonstrated that stimulation of different acupuncture points, for example, LI 4 (Hegu) or 
Liv 3 (Taichong) induced specific patterns of brain activity in adults [17] and children [18]. This brain pattern activation is based on the indirect representation of neuronal activity and metabolic changes, particularly the relative changes in concentration of deoxygenated haemoglobin ( $\mathrm{HHb}$ ). Nearinfrared spectroscopy (NIRS) has been used to measure cerebral tissue oxygenation and changes in oxygen delivery and oxygen consumption within a tissue compartment [19]. In 1978, Chen and Erdmann [20] firstly described the effects of acupuncture on oxygenation, followed by several studies demonstrating the effect of acupuncture using NIRS in adults [21] and concluded that changes in peripheral and cerebral activities can be quantified and are reproducible using NIRS. The limited evidence of LA studies in children shows similar results compared to adults $[22,23]$. However, the central effect of LA in newborn infants has not been evaluated. The aim of the study was to measure changes of regional cerebral tissue oxygenation in term and preterm neonates undergoing LA.

\section{Materials and Methods}

2.1. Participants. Preterm and term newborns admitted to the Neonatal Intensive Care Unit of the University Hospital of Graz scheduled for sleep studies were included. Infants were excluded with known genetic anomalies or major malformations, pathology in cranial ultrasound or abnormal neurological examination, elevated bilirubin levels, suspected intrauterine infection, and suspected sepsis or septic shock. Infants $>28$ weeks gestation were also excluded if they had any need for respiratory support or oxygen during study phase. Infants $<28$ weeks gestation were only included if they required $<30 \%$ oxygen or had only needed continuous positive airway pressure. The university ethics committee approved the study, and parental written informed consent was obtained.

Measurements were performed after 2 hours of undisturbed daytime sleep in supine position using a Babytherm 8000 incubator (Dräger GmbH Lübeck, Germany). During the measurements no medication was administered; the ambient temperature and humidity were kept constant. The infant was comforted with a pacifier if needed, and the eyes were protected with an eye shield (Biliband, Natus Medical Inc., San Carlos, CA, USA) as previously described [24].

Heart rate, oxygen saturation, and breathing movements were recorded. Cerebral oxygenation was measured using NIRO 300 (Hamamatsu, Japan). The optodes were placed on the left side of the forehead with an interoptode distance of $4 \mathrm{~cm}$ and a sampling rate of $2 / \mathrm{s}$. Light shielding was performed with a slim cap.

The NIRO 300 continuously measures changes in the oxyhemoglobin $\left(\mathrm{O}_{2} \mathrm{Hb}\right)$, deoxyhemoglobin $(\mathrm{HHb})$ concentration, and regional oxygen saturation $\left(\mathrm{rSO}_{2}\right.$ (the NIRO 3 oo displays the regional oxygen saturation as "tissue oxygen index (TOI)"). Measurement of $\mathrm{rSO}_{2}$ was performed using the Spatially Resolved Spectroscopy (SRS) method, in which the tissue absorption coefficient is determined from the regionally dependent weakening of light. A detector

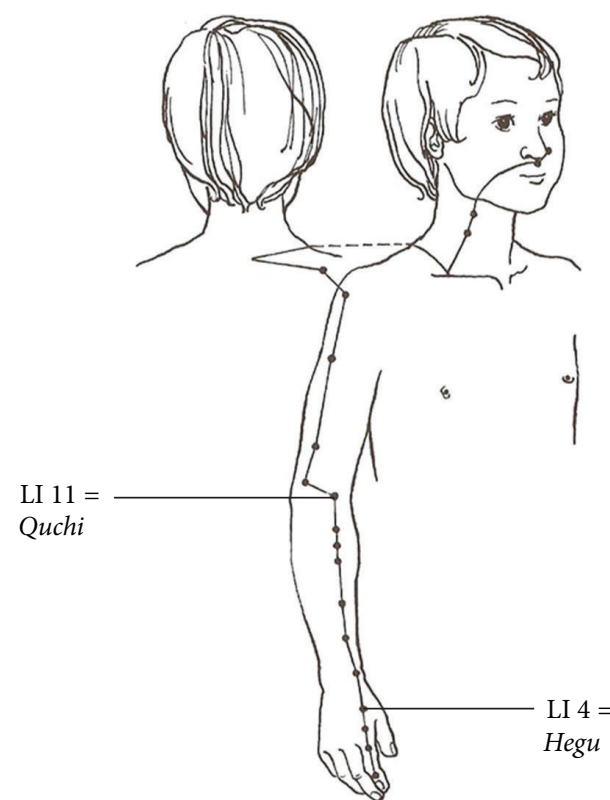

FIgURE 1: LI $4(\mathrm{Hegu})$ is located in the Large Intestine Meridian in the middle of the 2 nd metacarpal bone on the radial side. The Large Intestine Meridian begins on the index finger and travels along the arm over the shoulder to end outside of the nose. LI 4 (Hegu) is considered to be one of the most effective acupuncture points for general pain control, especially of the head. Modified by the author H. Tenk: Internship of Pediatric Chinese Acupuncture, 3 ed, W. Maudrich, 1994.

especially developed for the SRS method registers the emitted near-infrared light from the light source into tissue and allowed $\mathrm{rSO}_{2}$ calculation using the SRS algorithm. All parameters were stored within a multichannel system.

As acupuncture point Large Intestine 4 (LI 4, Hegu) was selected. LI 4 (Hegu) is located in the Large Intestine Meridian in the middle of the 2nd metacarpal bone on the radial side (Figure 1). There are a total of 20 points on the Large Intestine Meridian. The pathway begins at the index finger along the arm over the shoulder and ends on the face just lateral of the nose. For LA, a laser needle (laser needle $\mathrm{GmbH}$, Glienicke/Nordbahn, Germany) was used, which has been previously described by Litscher et al. [25-27].

The laser needle used for acupuncture provides continuous laser light with a wavelength of $685 \mathrm{~nm}$ and an output power of $10 \mathrm{~mW}$ per laser needle. An output power of $10 \mathrm{~mW}$ (diameter $500 \mu \mathrm{m}$ ) and a radiation time of $5 \mathrm{~min}$ resulted in an power density of about $1,5 \mathrm{~J} / \mathrm{cm}^{2}$ per acupuncture point [27].

Before LA was performed, the skin at the acupuncture point was disinfected, and the laser needles were fixed to the skin with a special adhesive tape, bilaterally at LI 4 ( Hegu). Once the baby fell asleep, the fixed laser needle was activated for 5 minutes and left undisturbed on the child's LI 4 (Hegu), bilaterally (for at least 10 minutes).

Figure 2 shows the infant with the applied and activated laser needle. 


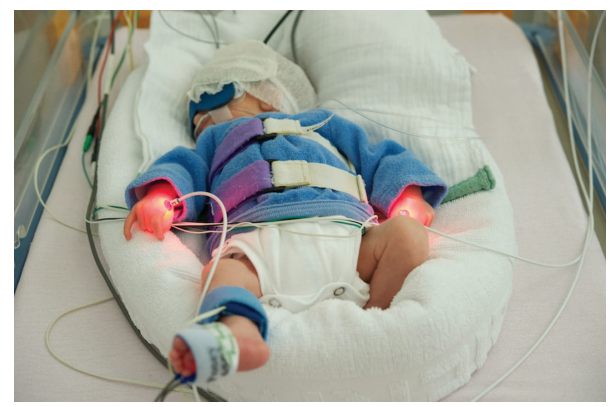

FIgURE 2: Demonstrates the infant with the applied laser needle and the near-infrared spectroscopy monitoring secured through the slim cap.

To include data in the analysis, there had to be, a "stable period" lasting 3 min before activating the laser needle without body movements, without apnoea or periodic breathing, without variations in heart rate exceeding $15 \%$, and without variations in oxygen saturation measurements. For further analysis, NIRS parameters were recorded before, during, and after laser needle acupuncture with a sampling rate $2 / \mathrm{sec}$.

The prospective protocol consisted of two baseline periods, each lasting 5 minutes, one before (preintervention period), one after intervention (postintervention period). To depict dynamic changes during intervention, the intervention period was divided into 10 periods, each lasting 30 seconds. Mean values of peripheral oxygen saturation $\left(\mathrm{SpO}_{2}\right)$, heart rate $(\mathrm{HR})$, regional cerebral oxygen saturation $\left(\mathrm{rcSO}_{2}\right)$ were calculated for the two baseline periods, as well as for the 10 intervention periods. Cerebral fractional tissue oxygen extraction (cFTOE) was calculated for each period $\left(\left(\mathrm{SpO}_{2}-\right.\right.$ $\left.\mathrm{rcSO}_{2}\right) / \mathrm{SpO}_{2}$ ) [28]. Data are presented as mean and $95 \%$ confidence interval. In this analysis, we investigated the changes in $\mathrm{SpO}_{2}, \mathrm{HR}, \mathrm{rcSO}_{2}$, and $\mathrm{cFTOE}$ within the intervention period compared to preintervention and postintervention periods using a linear mixed model with a fixed effect for time and a first order autoregressive covariance structure. A $P$ value of $<0.05$ was considered as a statistical significance. The statistical analyses were performed using IBM SPSS Statistics (release 19.0.0. 2010, Chicago, IL, USA, SPSS Inc., an IBM company).

\section{Results and Discussion}

3.1. Results. The study group encompassed 20 neonates with a gestational age ranging from $26^{6 / 7}$ to $40^{6 / 7}$ weeks and a birth weight of 690 to $3680 \mathrm{~g}$. Mean (range) measurements were performed on day 22 (11-68) after birth. Table 1 shows the demographic data of the study population.

We did not observe any significant changes in $\mathrm{SpO}_{2}$ and $\mathrm{HR}$ values during the whole observation period. However, there was a significant decrease in $\operatorname{rcSO}_{2}(P=0.003)$ within postintervention period, accompanied by a significant increase in cFTOE $(P=0.010)$ in postintervention period (Figures 3 and 4 ).
TABLE 1: Values are median and range for continuous data and absolute counts for categorical data.

\begin{tabular}{lc}
\hline Investigated neonates & $N=20$ \\
\hline Male/female & $12 / 8$ \\
Preterm/term & $17 / 3$ \\
Birthweight & $2120 \mathrm{~g}(690 \mathrm{~g}-3600 \mathrm{~g})$ \\
AGA/SGA & $19 / 1$ \\
GA (in completed weeks) & $34+0(27-40)$ \\
Day of life at the time of investigation & $22(11-68)$ \\
GA (in completed weeks) at the time of & $37+2(34-42)$ \\
investigation & \\
Weight at the time of investigation & $2353 \mathrm{~g}(1882-3685 \mathrm{~g})$ \\
HCT in \% & $43.4 \%$
\end{tabular}

GA: gestational age; AGA: appropriate for date; SGA: small for date; HCT: hematocrit.

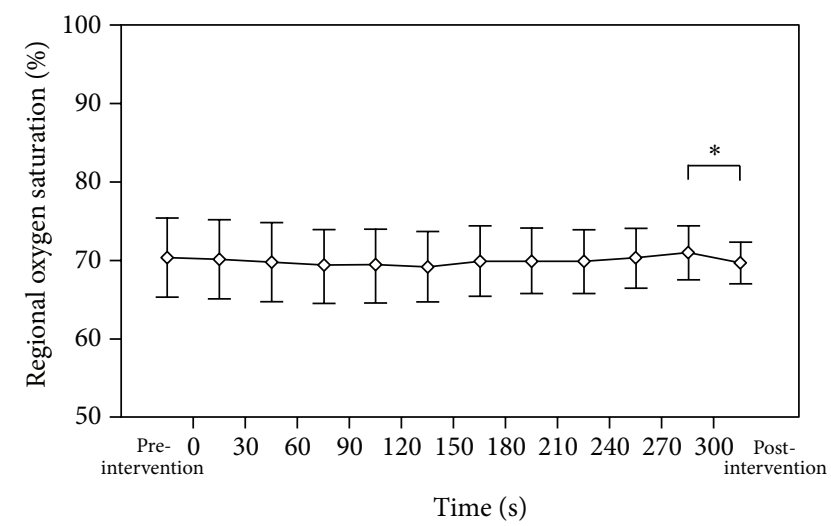

FIGURE 3: There was a significant decrease in regional cerebral oxygen saturation $\left(\mathrm{rcSO}_{2}\right)$ during postintervention period $(P=$ $0.003)$.

3.2. Discussion. There is an increasing interest in complementary medical treatment of infants and newborn; however, the evidence is scare. A recent meta-analysis demonstrated that [29] acupuncture could be a safe nonpharmacologic treatment option for pain reduction in term and preterm infants. The current study investigated cerebral oxygenation and physiological parameter during LA. The results of the study can be summarised as follows: (i) significant decrease in regional cerebral oxygen saturation $\left(\mathrm{rcSO}_{2}\right)$ in postintervention period, (ii) significant increase in cerebral fractional tissue oxygen extraction (cFTOE), and (iii) no changes at all in peripheral oxygen saturation or heart rate during the whole observation period. This is the first study to demonstrate changes in cerebral tissue oxygenation in association with LA in term and preterm infants.

Oxygen delivery is the product of blood flow and oxygen content. In neonates, the cardiac output is dependent on HR. In our study, there were no significant differences in $\mathrm{HR}$, which leads us to assume that there were no differences between both groups as regards to blood flow. The oxygen content of arterial blood supplying the brain equates $\mathrm{SpO}_{2}$, which did not show any significant changes either. Therefore, 


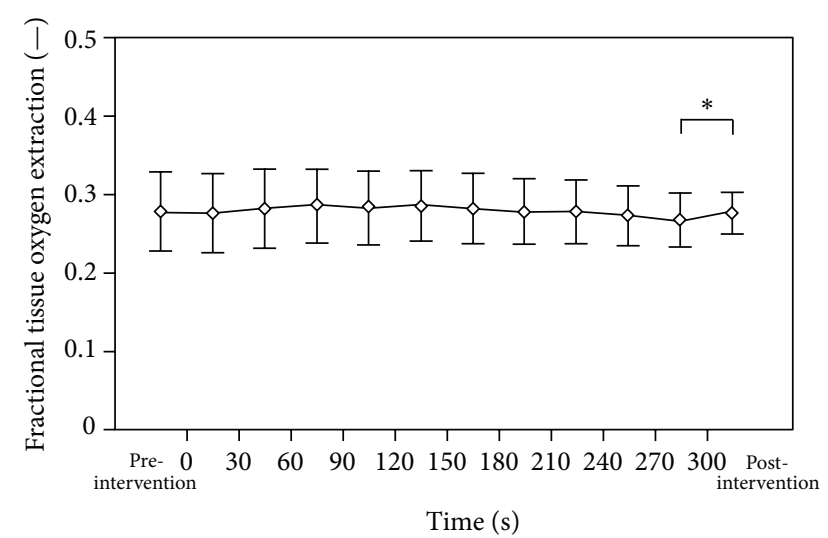

FIgURE 4: There was a significant increase in the cerebral fractional tissue oxygen extraction (cFTOE) during postintervention period $(P=0.010)$.

we hypothesize that the observed significant changes in $\mathrm{rCSO}_{2}$ and cFTOE were due to changes in regional cerebral tissue perfusion and oxygen extraction. Our findings suggest that there was a decrease in local arterial blood supply after discontinuation of LA, expressed in a decrease of $\mathrm{rcSO}_{2}$. This was accompanied by an increase in regional tissue oxygen extraction, expressed in an increase of cFTOE. Furthermore, we hypothesize that the increase of local cerebral tissue perfusion may have been a slow process, and that may be the reason why there were no significant changes measureable during LA. There are some similarities to reported results of LA in adults [27, 30]. Litscher and Wang reported an increase of $\mathrm{O}_{2} \mathrm{Hb}$ and TOI after needle and laser acupuncture in adult patients [31]. Furthermore, Litscher described a possible correlation between manual needle acupuncture, laser acupuncture, electrical punctual stimulation, and changes in regional cerebral oxygenation in more than 100 volunteers [32].

LI 4 (Hegu), which is considered to be one of the most effective acupuncture points for general pain control, was used in the current study. Manual acupuncture applied to LI 4 (Hegu) activates the sympathetic and parasympathetic nervous systems in healthy individuals [33]. Stimulating LI 4 (Hegu) bilaterally resulted in a more immediate effect than unilateral stimulation [34]. LI 4 (Hegu) has been used to treat infantile colic [35-38] and has been described for analgesia [39]. Furthermore, LI 4 (Hegu) induces specific patterns of brain activity in adults and children during manual acupuncture, electroacupuncture, and LA [40, 41]. These investigations are based on the indirect representation of neuronal activity and the resulting metabolic changes, particularly the relative changes in concentration of HHb. NIRS is an established approach to noninvasive measure peripheral and cerebral tissue oxygenation [42]. Near-infrared light penetrates deep into the tissue allowing to monitor tissue oxygenation. The oxygen-dependent absorption of light by haemoglobin enables the calculation of relative changes in the oxygenated and deoxygenated haemoglobin [43]. The advantages of NIRS are (i) noninvasive, (ii) low risk, (iii) continuity, and (iv) particularly suitable for the neonatal population due to their thin scalp and skull. The application of the method is easy, and it is used in several studies to measure cerebral [44-46] and peripheral oxygenation in term and preterm newborn $[47,48]$. Our results demonstrate that NIRS can be used to measure changes of cerebral tissue oxygenation in term and preterm neonates undergoing LA.

Currently there are only a few studies that investigated the effect of acupuncture in neonates [49]. In children, acupuncture has been demonstrated to have positive effects on pain $[39,50,51]$. In comparison, there is a lack of data in newborn infants about safety of acupuncture and the response to acupuncture. Current evidence suggests that acupuncture is a safe modality for pediatric patients. However, fewer needles should be used when treating infants compared to adults $[52,53]$. Case reports and case series have been described for neonates, and early infancy has been carried out, for example, as a therapy for infantile colic [35$38,54]$, pain treatment, and newborn abstinence syndrome $[55,56]$. A major limitation of acupuncture in newborns is their skin vulnerability with a potential to damage the skin resulting in a potential entry wound for infectious diseases. It is also unknown whether repeated needle stimulation may alter sensory processing and responses to subsequent painful stimuli, in the same manner like heel sticks, necessary to take blood samples $[6,39,57]$. LA is a painless procedure, and therefore, it becomes a more and more relevant alternative to manual acupuncture in infants [7-14]. But the central and peripheral effects and the applied doses in neonates and infants undergoing laser acupuncture are a matter of fact in ongoing discussions. Recently, acupuncture was considered to be included in the pain management algorithm for children as an effective nonpharmacological approach $[58,59]$.

The current study has some additional limitation not previously mentioned. The acupuncture effect of laser stimulation depends on the power density at the acupuncture point.

For a laser output power of $10 \mathrm{~mW}$, the resulting power density at the acupuncture point is in the order of $5 \mathrm{~W} / \mathrm{cm}^{2}$. An output power of $10 \mathrm{~mW}$ and a time of radiation of $5 \mathrm{~min}$ result in an energy dosage of about $1,5 \mathrm{~J} / \mathrm{cm}^{2}$. Maybe with a higher energy dosage (higher laser output power and/or a longer radiation time) the results could be more significant, especially during LA [27].

But based on our recent published data about the changes of the skin temperature in preterm infants undergoing laser acupuncture [15], it seems rational and safe to use the same laser needle with the same output power $(10 \mathrm{~mW})$ and the same time of stimulation (five minutes). Another limitation of our study was the small number of infants included in the study. Future research should focus on alternative or adjunctive nonpharmacological therapy to understand the utility, safety, and effectiveness of acupuncture in newborns and infants and investigate central effects of LA in neonates, by changing the time of stimulation and/or the energy doses.

\section{Conclusions}

There was a significant decrease in $\mathrm{rcSO}_{2}$ during postintervention period. This was accompanied by a significant 
increase in cFTOE. This was in contrast to $\mathrm{SpO}_{2}$ and $\mathrm{HR}$, where no changes could be observed. Therefore, we hypothesize that observed changes were due to changes in regional cerebral perfusion and oxygen supply. This is the first study to demonstrate changes of cerebral tissue oxygenation caused by laser acupuncture in term and preterm neonates.

$\begin{array}{ll}\text { Abbreviations } \\ \text { CAM: } & \text { Complementary and alternative medicine } \\ \text { TCM: } & \text { Traditional Chinese medicine } \\ \text { LA: } & \text { Laser acupuncture } \\ \text { NIRS: } & \text { Near-infrared spectroscopy } \\ \mathrm{O}_{2} \mathrm{Hb}: & \text { Oxyhemoglobin } \\ \mathrm{HHb}: & \text { Deoxyhemoglobin } \\ \mathrm{TOI}: & \text { Tissue oxygenation index } \\ \mathrm{HR}: & \text { Heart rate } \\ \mathrm{SpO}: & \text { Peripheral oxygen saturation } \\ \mathrm{rSO}_{2}: & \text { Regional oxygen saturation } \\ \mathrm{rcSO}_{2}: & \text { Regional cerebral oxygen saturation } \\ \mathrm{cFTOE}: & \text { Cerebral fractional tissue oxygenation } \\ \mathrm{SRS} & \text { Spatial resolved spectroscopy } \\ \mathrm{LI}_{4}(\mathrm{Hegu}): & \text { Large Intestine } 4\end{array}$

\section{Disclosure}

The authors do not have any commercial associations that might create a conflict of interests in connection with this paper. They thank the parents for allowing them to study their infants, and the nurses involved in the treatment of the neonates. They also thank Evelyne Ziehenberger for her help in the realization of the study.

\section{References}

[1] E. Ernst, "Prevalence of complementary/alternative medicine for children: a systematic review," European Journal of Pediatrics, vol. 158, no. 1, pp. 7-11, 1999.

[2] S. Vohra, S. Surette, D. Mittra, L. D. Rosen, P. Gardiner, and K. J. Kemper, "Pediatric integrative medicine: paediatrics? Newest subspecialty?" BMC Pediatrics, vol. 12, no. 1, article 123, 2012.

[3] J. Snyder and P. Brown, "Complementary and alternative medicine in children: an analysis of the recent literature," Current Opinion in Pediatrics, vol. 24, no. 4, pp. 539-546, 2012.

[4] M. Loo, Pediatric Acupuncture, Churchill Livingstone, New York, NY, USA, 2002.

[5] K. Hunt and E. Ernst, "The evidence-base for complementary medicine in children: a critical overview of systematic reviews," Archives of Disease in Childhood, vol. 96, no. 8, pp. 769-776, 2011.

[6] A. Taddio, V. Shah, C. Gilbert-MacLeod, and J. Katz, "Conditioning and hyperalgesia in newborns exposed to repeated heel lances," The Journal of the American Medical Association, vol. 288, no. 7, pp. 857-861, 2002.

[7] W. Raith, G. Litscher, W. Müller, and B. Urlesberger, "Laseracupuncture-a possible alternative treatment for agitation and pain in neonates?" Pediatric Anesthesia, vol. 23, no. 2, pp. 205-206, 2013.

[8] J. Zhang, X. Li, J. Xu, and E. Ernst, "Laser acupuncture for the treatment of asthma in children: a systematic review of randomized controlled trials," Journal of Asthma, vol. 49, no. 7, pp. 773-777, 2012.

[9] M. I. Karaman, O. Koca, E. V. Küçük, M. Öztürk, M. Güneş, and C. Kaya, "Laser acupuncture therapy for primary monosymptomatic nocturnal enuresis," Journal of Urology, vol. 185, no. 5, pp. 1852-1856, 2011.

[10] E. Radvanska, K. Kamperis, A. Kleif, L. Kovács, and S. Rittig, "Effect of laser acupuncture for monosymptomatic nocturnal enuresis on bladder reservoir function and nocturnal urine output," Journal of Urology, vol. 185, no. 5, pp. 1857-1861, 2011.

[11] S. Gottschling, S. Meyer, I. Gribova et al., "Laser acupuncture in children with headache: a double-blind, randomized, bicenter, placebo-controlled trial," Pain, vol. 137, no. 2, pp. 405-412, 2008.

[12] K. Stockert, B. Schneider, G. Porenta, R. Rath, H. Nissel, and I. Eichler, "Laser acupuncture and probiotics in school age children with asthma: a randomized, placebo-controlled pilot study of therapy guided by principles of traditional Chinese medicine," Pediatric Allergy and Immunology, vol. 18, no. 2, pp. 160-166, 2007.

[13] W. Gruber, E. Eber, D. Malle-Scheid et al., "Laser acupuncture in children and adolescents with exercise induced asthma," Thorax, vol. 57, no. 3, pp. 222-225, 2002.

[14] A. Stellon, "The use of laser acupuncture for the treatment of neurogenic pruritus in a child-a case history," Acupuncture in Medicine, vol. 23, no. 1, pp. 31-33, 2005.

[15] W. Raith, G. Litscher, I. Sapetschnig et al., “Thermographical measuring of the skin temperature using laser needle acupuncture in preterm neonates," Evidence-Based Complementary and Alternative Medicine, vol. 2012, Article ID 614210, 5 pages, 2012.

[16] R. T. Chow, "Dose dilemmas in low level laser therapy-the effects of different paradigms and historical perspectives," Laser Therapy Journal, no. 13, pp. 102-108, 2012.

[17] W. Huang, D. Pach, V. Napadow et al., "Characterizing acupuncture stimuli using brain imaging with FMRI-a systematic review and meta-analysis of the literature," PLoS ONE, vol. 7, no. 4, Article ID e32960, 2012.

[18] Y. Wu, Z. Jin, K. Li et al., "Functional magnetic resonance imaging activation of the brain in children: real acupoint versus sham acupoint," Journal of Child Neurology, vol. 25, no. 7, pp. 849-855, 2010.

[19] F. F. Jöbis, "Noninvasive, infrared monitoring of cerebral and myocardial oxygen sufficiency and circulatory parameters," Science, vol. 198, no. 4323, pp. 1264-1267, 1977.

[20] G. S. Chen and W. Erdmann, "Effects of acupuncture on tissue oxygenation of the rat brain," Southern Medical Journal, vol. 71, no. 4, pp. 392-398, 1978.

[21] G. Litscher, L. Wang, and E. Huber, "Changes in cerebral near infrared spectroscopy parameters during manual acupuncture needle stimulation," Biomedizinische Technik, vol. 47, no. 4, pp. 76-79, 2002 (German).

[22] G. Litscher, "NIR spectroscopy explores the mysteries of acupuncture," Spectroscopy Europe, vol. 17, no. 1, pp. 8-14, 2005.

[23] G. Litscher, "NIR spectroscopy explores the mysteries of acupuncture," Spectroscopy Asia, vol. 1, no. 1, pp. 8-14, 2005.

[24] W. Raith, G. M. Schmölzer, B. Resch, M. Seewann, W. Müller, and B. Urlesberger, "Laser acupuncture as a possible treatment for an agitated infant-a preterm after 28 weeks of gestation," German Journal of Acupuncture and Related Techniques, vol. 51, no. 3, pp. 33-36, 2008.

[25] G. Litscher and D. Schikora, "Cerebral vascular effects of noninvasive laserneedles measured by transorbital and transtemporal Doppler sonography," Lasers in Medical Science, vol. 17, no. 4, pp. 289-295, 2002. 
[26] G. Litscher, "Cerebral and peripheral effects of laserneedlestimulation," Neurological Research, vol. 25, no. 7, pp. 722-728, 2003.

[27] G. Litscher and D. Schikora, Eds., Laserneedle-Acupuncture: Science and Practice, Pabst Science, Berlin, Germany, 2005.

[28] G. Naulaers, B. Meyns, M. Miserez et al., "Use of tissue oxygenation index and fractional tissue oxygen extraction as non-invasive parameters for cerebral oxygenation: a validation study in piglets," Neonatology, vol. 92, no. 2, pp. 120-126, 2007.

[29] W. Raith, B. Urlesberger, and G. M. Schmölzer, "Efficacy and safety of acupuncture in preterm and term infants," EvidenceBased Complementary and Alternative Medicine, 2013.

[30] G. Litscher and D. Schikora, "Near-infrared spectroscopy for objectifying cerebral effects of needle and laserneedle acupuncture," Spectroscopy, vol. 16, no. 3-4, pp. 335-342, 2002.

[31] G. Litscher and L. Wang, "Cerebral near infrared spectroscopy and acupuncture-results of a pilot study," Biomedizinische Technik, vol. 45, no. 7-8, pp. 215-218, 2000.

[32] G. Litscher, "Bioengineering assessment of acupuncture-part 5: cerebral near-infrared spectroscopy," Critical Reviews in Biomedical Engineering, vol. 34, no. 6, pp. 439-457, 2006.

[33] E. Haker, H. Egekvist, and P. Bjerring, "Effect of sensory stimulation (acupuncture) on sympathetic and parasympathetic activities in healthy subjects," Journal of the Autonomic Nervous System, vol. 79, no. 1, pp. 52-59, 2000.

[34] T. B. Lin and T. C. Fu, "Effect of electroacupuncture on blood pressure and adrenal nerve activity in anesthetized rats," Neuroscience Letters, vol. 285, no. 1, pp. 37-40, 2000.

[35] K. Landgren, N. Kvorning, and I. Hallström, "Acupuncture reduces crying in infants with infantile colic: a randomised, controlled, blind clinical study," Acupuncture in Medicine, vol. 28, no. 4, pp. 174-179, 2010.

[36] K. Landgren, N. Kvorning, and I. Hallström, “Feeding, stooling and sleeping patterns in infants with colic-a randomized controlled trial of minimal acupuncture," BMC Complementary and Alternative Medicine, vol. 11, article 93, 2011.

[37] M. Reinthal, S. Andersson, M. Gustafsson et al., "Effects of minimal acupuncture in children with infantile colic-a prospective, quasi-randomised single blind controlled trial," Acupuncture in Medicine, vol. 26, no. 3, pp. 171-182, 2008.

[38] M. Reinthal, I. Lund, D. Ullman, and T. Lundeberg, "Gastrointestinal symptoms of infantile colic and their change after light needling of acupuncture: a case series study of 913 infants," Chinese Medicine, vol. 6, article 28, 2011.

[39] A. Ecevit, D. A. Ince, A. Tarcan, M. T. Cabioglu, and A. Kurt, "Acupuncture in preterm babies during minor painful procedures," Journal of Traditional Chinese Medicine, vol. 31, no. 4, pp. 308-310, 2011.

[40] W. Wang, L. Liu, X. Zhi et al., "Study on the regulatory effect of electro-acupuncture on Hegu point (LI4) in cerebral response with functional magnetic resonance imaging," Chinese Journal of Integrative Medicine, vol. 13, no. 1, pp. 10-16, 2007.

[41] C. M. Siedentopf, F. Koppelstaetter, I. A. Haala et al., "Laser acupuncture induced specific cerebral cortical and subcortical activations in humans," Lasers in Medical Science, vol. 20, no. 2, pp. 68-73, 2005.

[42] J. Menke, U. Voss, G. Möller, and G. Jorch, "Reproducibility of cerebral near infrared spectroscopy in neonates," Biology of the Neonate, vol. 83, no. 1, pp. 6-11, 2003.

[43] M. Wolf and G. Greisen, "Advances in near-infrared spectroscopy to study the brain of the preterm and term neonate," Clinics in Perinatology, vol. 36, no. 4, pp. 807-834, 2009.
[44] B. Urlesberger, G. Pichler, E. Gradnitzer, F. Reiterer, G. Zobel, and W. Müller, "Changes in cerebral blood volume and cerebral oxygenation during periodic breathing in term infants," Neuropediatrics, vol. 31, no. 2, pp. 75-81, 2000.

[45] G. Pichler, M. C. van Boetzelar, W. Müller, and B. Urlesberger, "Effect of tilting on cerebral hemodynamics in preterm and term infants," Biology of the Neonate, vol. 80, no. 3, pp. 179-185, 2001.

[46] N. Tax, G. Pichler, K. Grossauer et al., "Tilting the head changes cerebral haemodynamics in neonates," Neonatology, vol. 100, no. 3, pp. 253-259, 2011.

[47] G. Pichler, K. Grossauer, P. Klaritsch et al., "Peripheral oxygenation in term neonates," Archives of Disease in Childhood: Fetal and Neonatal Edition, vol. 92, no. 1, pp. F51-F52, 2007.

[48] G. Pichler, J. Heinzinger, P. Klaritsch, H. Zotter, W. Müller, and B. Urlesberger, "Impact of smoking during pregnancy on peripheral tissue oxygenation in term neonates," Neonatology, vol. 93, no. 2, pp. 132-137, 2008.

[49] M. T. Thiel and K. Stockert, "Acupuncture and neonatology," Journal of Chinese Medicine, no. 97, pp. 50-57, 2011.

[50] K. J. Kemper, R. Sarah, E. Silver-Highfield, E. Xiarhos, L. Barnes, and C. Berde, "On pins and needles? Pediatric pain patients' experience with acupuncture," Pediatrics, vol. 105, no. 4, pp. 941947, 2000.

[51] H. Jun, Z. Cuiping, and C. Shunhai, "Electric acupuncture treatment of peripheral nerve injury," Journal of Traditional Chinese Medicine, vol. 15, pp. 114-117, 1995.

[52] V. Jindal, A. Ge, and P. J. Mansky, "Safety and efficacy of acupuncture in children: a review of the evidence," Journal of Pediatric Hematology/Oncology, vol. 30, no. 6, pp. 431-442, 2008.

[53] D. Adams, F. Cheng, H. Jou, S. Aung, Y. Yasui, and S. Vohra, "The safety of pediatric acupuncture: a systematic review," Pediatrics, vol. 128, no. 6, pp. 1575-1587, 2011.

[54] H. Skjeie, T. Skonnord, A. Fetveit, and M. Brekke, "A pilot study of ST36 acupuncture for infantile colic," Acupuncture in Medicine, vol. 29, no. 2, pp. 103-107, 2011.

[55] B. Golianu, E. Krane, J. Seybold, C. Almgren, and K. J. S. Anand, "Non-pharmacological techniques for pain management in neonates," Seminars in Perinatology, vol. 31, no. 5, pp. 318-322, 2007.

[56] W. Raith, G. Pichler, H. Zotter, W. Mueller, and B. Urlesberger, "Detection of psychic ear acupuncture points in a newborn infant with neonatal abstinence syndrome," Journal of Alternative and Complementary Medicine, vol. 16, no. 4, pp. 345-346, 2010.

[57] K. R. . Gentry, K. L. McGinn, A. Kundu, and A. M. Lynn, "Acupuncture therapy for infants: a preliminary report on reasons for consultation, feasibility, and tolerability," Pediatric Anesthesia, vol. 22, no. 7, pp. 690-695, 2012.

[58] V. Y. Sohn, D. Zenger, and S. R. Steele, "Pain management in the pediatric surgical patient," Surgical Clinics of North America, vol. 92, no. 3, pp. 471-485, 2012.

[59] J. C. I. Tsao, S. Evans, M. Meldrum, T. Altman, and L. K. Zeltzer, "A review of CAM for procedural pain in infancy-part II: other interventions," Evidence-Based Complementary and Alternative Medicine, vol. 5, no. 4, pp. 399-407, 2008. 


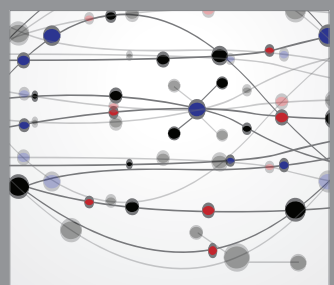

The Scientific World Journal
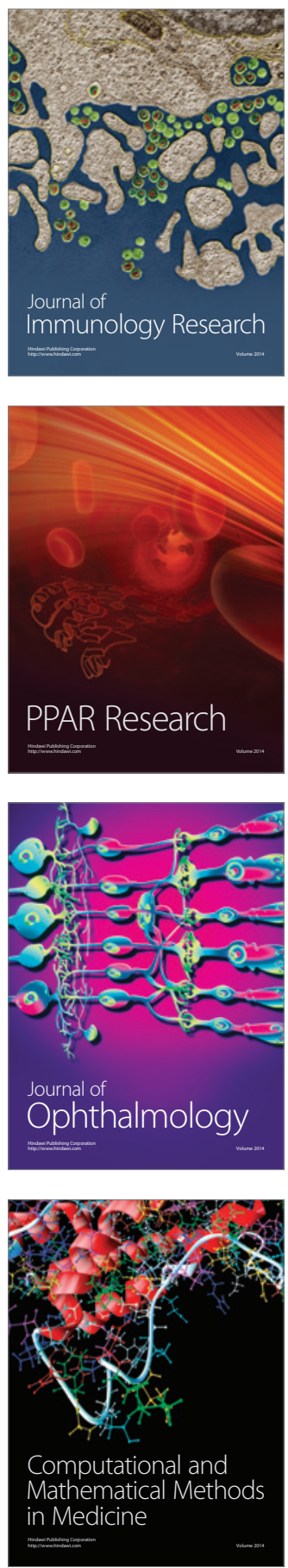

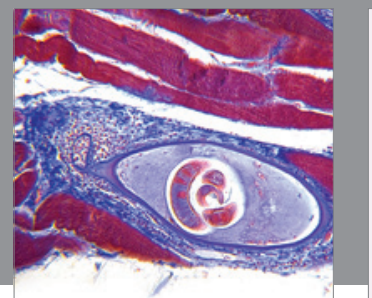

Gastroenterology

Research and Practice
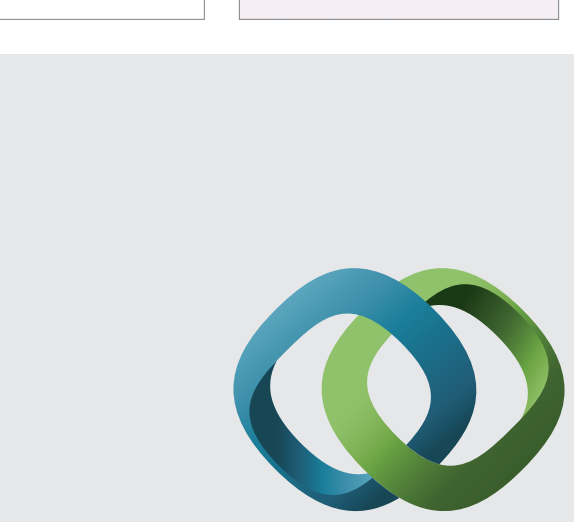

\section{Hindawi}

Submit your manuscripts at

http://www.hindawi.com
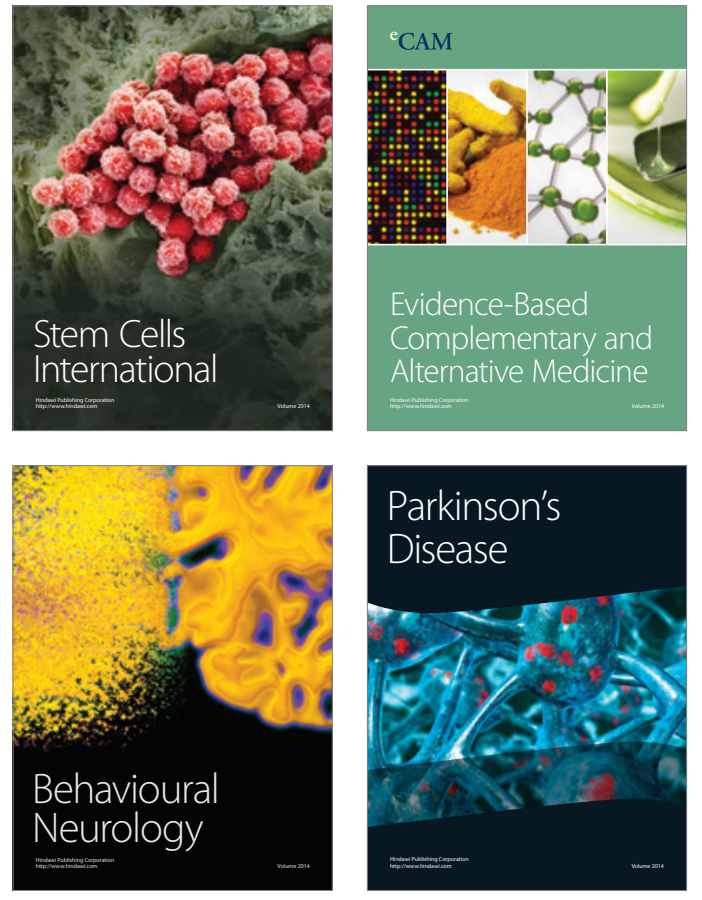
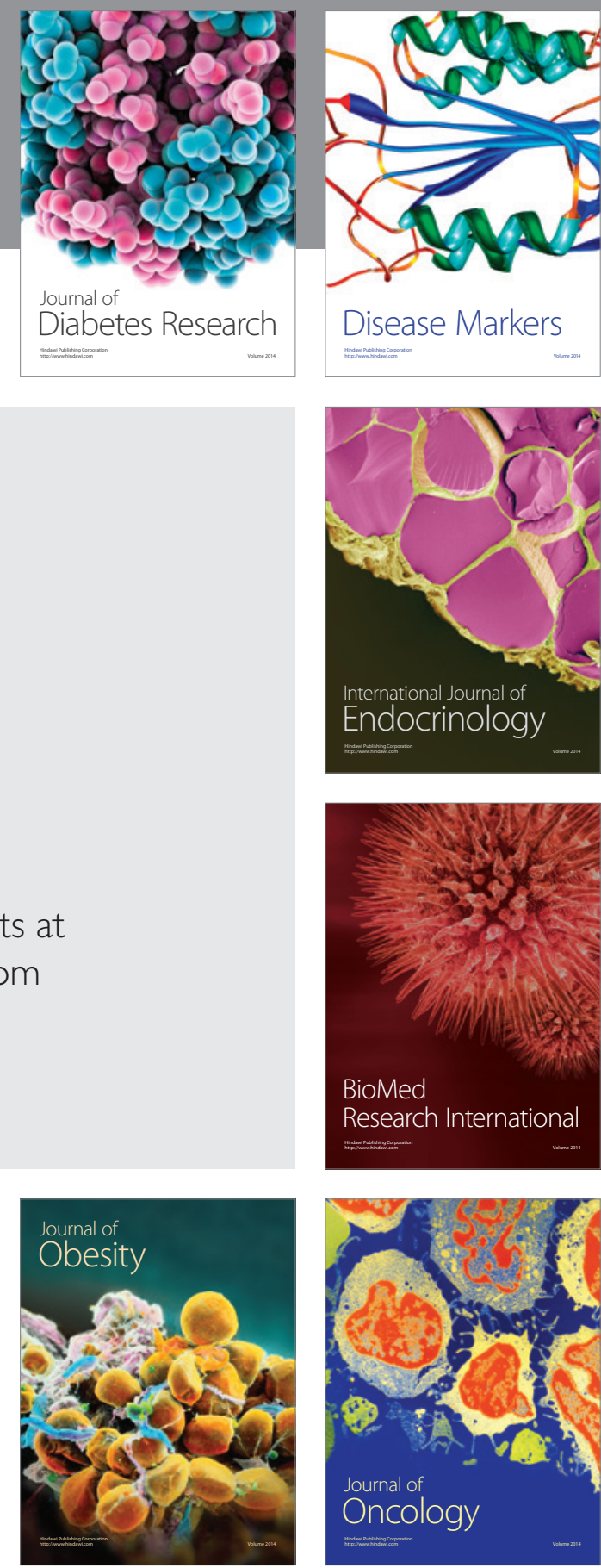

Disease Markers
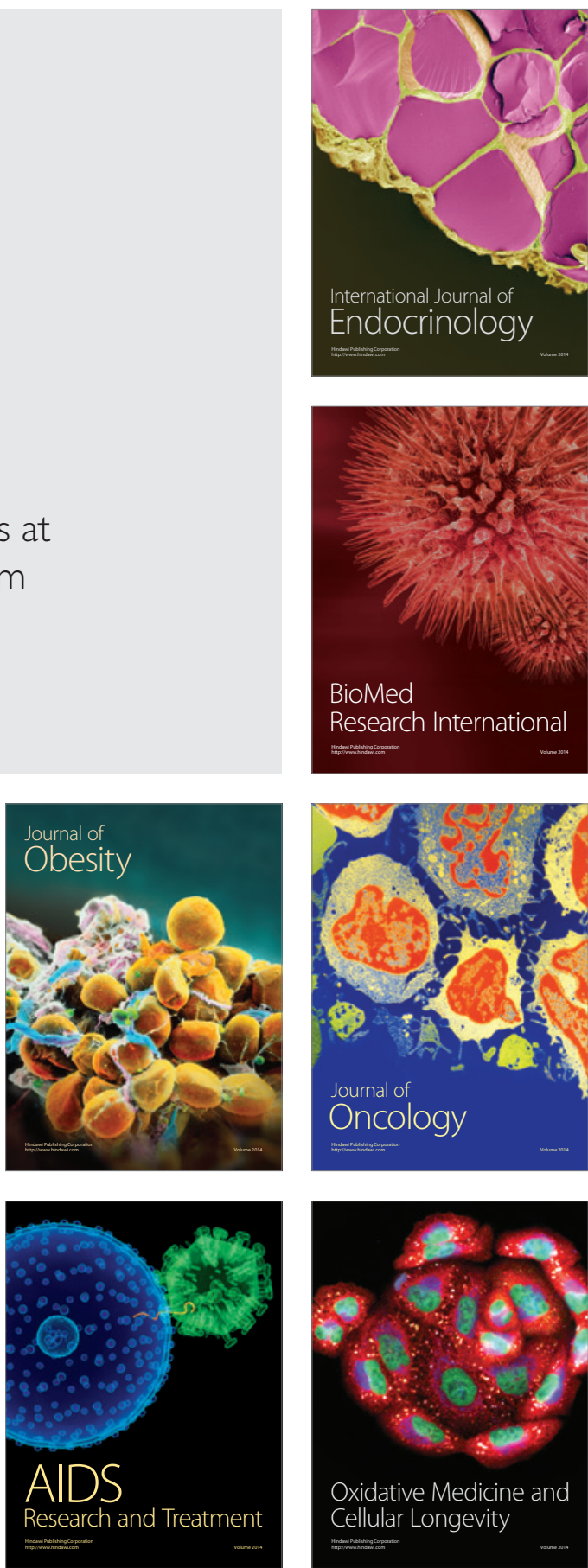